Article

\title{
Ongoing Colonization and Indigenous Environmental Heritage Rights: A Learning Experience with Cree First Nation Communities, Saskatchewan, Canada
}

\author{
Ranjan Datta ${ }^{1, *(\mathbb{D})}$ and William P. Marion ${ }^{2}$ \\ 1 Tier II in Community Disaster Research at Indigenous Studies, Department of Humanities, Mount Royal \\ University, Calgary, AB T3E 6K6, Canada \\ 2 Cree First Nation Knowledge Keeper from James Smith Cree Nation, Melfort, SK SOE 1A0, Canada; \\ wpm60@yahoo.ca \\ * Correspondence: rdatta@mtroyal.ca
}

check for updates

Citation: Datta, R.; Marion, W.P. Ongoing Colonization and Indigenous Environmental Heritage Rights: A Learning Experience with Cree First Nation Communities, Saskatchewan, Canada. Heritage 2021, 4,1388-1399. https://doi.org/ 10.3390/heritage4030076

Academic Editors: Claire Smith, Lilia Lucia Lizama, Israel Herrera and Alok Kumar Kanungo

Received: 1 June 2021

Accepted: 15 July 2021

Published: 20 July 2021

Publisher's Note: MDPI stays neutral with regard to jurisdictional claims in published maps and institutional affiliations.

Copyright: (c) 2021 by the authors. Licensee MDPI, Basel, Switzerland. This article is an open access article distributed under the terms and conditions of the Creative Commons Attribution (CC BY) license (https:// creativecommons.org/licenses/by/ $4.0 /)$.

\begin{abstract}
Ongoing colonization of the environment and natural resources has negatively impacted environmental heritage rights in many parts of the world, particularly Indigenous environmental rights and their relationships with the environment. For many Indigenous communities, the history of colonialism became a history of dispossession for Indigenous peoples, their land, water, traditional knowledge, and practices. This paper addresses the ongoing environmental heritage conflict between the Cree First Nation communities' traditional environmental heritage practices and developmental energy projects in Saskatchewan, Canada. Drawing from a relational research framework, we (Cree First Nation Knowledge Keeper and settler scholar of color) shared our learning reflections from Cree First Nation communities on how energy projects (particularly pipeline leaks) have negatively impacted Indigenous land, water, and traditional heritage and practices. In this paper, we focus our learnings from the Cree First Nation communities on the following questions: Why and how do developmental projects neglect Indigenous heritage rights, particularly environmental heritage rights? What can be or should be done about it? What are our responsibilities as researchers and educators? In this study, we learned about traditional-knowledge-based consultation and solutions to the ongoing challenges of incorporating Indigenous interests into environmental heritage to foster Indigenous environmental heritage rights. We also highlight how Indigenous perspectives on their environmental heritage rights are interconnected with Sustainable Development Goals (SDGs) from our learning reflections, particularly Goal 3, Good Health and Wellbeing, Goal 10, Reduced Inequalities, Goal 13, Climate Action, Goal 15, Life on Land, and Goal 16, Peace, Justice, and Strong Institutions.
\end{abstract}

Keywords: Indigenous environmental heritage rights; environmental heritage; colonization; Cree First Nation; treaty rights; Indigenous perspectives

\section{Introduction}

Indigenous peoples are struggling for environmental heritage rights across the globe, particularly struggles for Indigenous land-water rights, language and cultural rights, sustainable development rights, relationships to environments, and rights on traditional practices. These struggles stem from centuries-long, ongoing colonial legacies. They hold profound significance for Indigenous peoples' environmental justice, environmental heritage, cultural identity, political autonomy and external relations within nation-states. Indigenous rights for environmental heritage has already been a long struggle.

The first international treaty, signed at the Hague Convention (1954), focused on protecting cultural property during armed conflicts. Article Two stated, "of the present Convention, the protection of cultural property shall comprise the safeguarding of and respect for such property." [1] The United Nations Educational, Scientific and Cultural 
Organization (UNESCO) 1970 Convention on the Means of Prohibiting and Preventing the Illicit Import, Export and Transfer of Ownership of Cultural Property is an international treaty [2]. The cultural rights treaty was signed on 14 November 1970, and came into force on 24 April 1972. In this treaty "intangible cultural heritage" is defined in four parts: first, oral traditions and expressions, including language; second, performing arts; third, social practices, rituals, and festive events; and fourth, traditional knowledge of nature, the universe, and traditional craftsmanship. In this treaty, the term "safeguarding" refers to ensuring the viability of intangible cultural heritage, including the identification, documentation, research, preservation, protection, promotion, enhancement, transmission, mainly through formal and non-formal education, and the revitalization of the various aspects of such heritage. Another term, "States Parties", refers to States bound by this Convention and where this Convention is in force. Article 33 (i.e., the territories) was added to the 1970 Convention as a condition of exercising a cultural right [2]. To that extent the expression "States Parties" also refers to such territories. After three decades, the UNESCO 2005 Convention for the Protection and Promotion of the Diversity of Cultural Expressions is:

a milestone in international cultural policy. Through this historic agreement, the global community formally recognized the dual nature, both cultural and economic, of contemporary cultural expressions produced by artists and cultural professionals. Shaping the design and implementation of policies and measures that support the creation, production, distribution of and access to cultural goods and services, the 2005 Convention is at the heart of the creative economy. [3]

The 2005 Convention supports government and civil society efforts to find policy solutions towards this aim. Based on human rights and fundamental freedoms, it provides "a new framework for informed, transparent and participatory systems of governance for culture." [4] (p. 1). The UN Declaration on the Rights of Indigenous Peoples by the UN General Assembly in September 2007 and the UN Development Group (UNDG) Guidelines on Indigenous Peoples' Issues issued in 2008 claimed that it is increasingly vital that UN agencies, including UNESCO, consider how to guide countries engaging with Indigenous peoples to protect Indigenous environmental heritage, culture, and language. UNESCO has broad mandates for Indigenous peoples worldwide (2018). UNESCO's “2030 Agenda commitment to Leave no one behind brings new impetus to ensure that indigenous peoples' priorities are heard" [5] (p. 1).

To implement UNESCO "2030" agendas, many Indigenous and non-Indigenous studies show [6-9] that Indigenous environmental knowledge and practices have been essential to global environmental, cultural, and economic diversity, but they continue to be marginalized and segregated from environmental heritage management policies. The environmental knowledge of Indigenous peoples and local communities-often referred to as local, Indigenous or traditional knowledge--is now recognized as essential, alongside science, for developing effective and meaningful action worldwide [5]. The UNESCO (2018) report shows that it has broad mandates in Indigenous environmental heritage protection. Its policies, programs, and projects provide opportunities for and have significant impacts (both positive and negative) on Indigenous peoples worldwide.

The UNESCO "2030" agendas suggest that the knowledge systems and environmental heritage management practices of Indigenous and local people provide insights enabling better management of ecological challenges, preventing biodiversity loss, reducing land degradation, and mitigating the effects of climate change. Environmental heritage culture, particularly traditional knowledge, also contributes to resilience and recovery in the case of disaster (target 13.1 of SDG 13). Indigenous environmental heritage rights and Sustainable Development Goals (SDGs) are deeply interconnected in several ways.

First, Indigenous traditional knowledge and resource management practices are interconnected through heritage to achieve the wellbeing of people (SDGs 1, 2, 3, 4, 5, 6, and 11). 
Second, Indigenous land-based approach in achieving their environmental heritage and the wellbeing of the planet (SDGs 6, 7, 11,13,14, and 15). Third, the shared resources embodied in heritage to achieve prosperity of communities (SDGs 5, 8, 9, 11, 12, and 14). Fourth, the relational meanings of environmental heritage for social cohesion and dialogue to achieve peace within and among societies (SDGs 10,11, and 16), and finally, the shared responsibilities to protect environmental heritage and its connections with all aspects of human life to create partnerships (SDGs 11 and 17). Indigenous community-engaged and community-led environmental heritage may be able to provide opportunities for meaningful implementation of SDGs.

In this paper, we search for a more critical examination of environmental heritage techniques previously thought of as neutral, and to bring those techniques under negotiation with many Indigenous communities. This paper critically discusses one Indigenous community's (i.e., Cree First Nations from North Saskatchewan, which is known as Treaty 6 territory (Many Cree First Nation communities have been living in Saskatchewan for thousands of years (for Interactive Map: https:/ / geo.aadnc-aandc.gc.ca/cippn-fnpim/indexeng.html (Accessed on 20 March 2021))) perspectives on an energy project, particularly Huskey Energy (https:/ / huskyenergy.com (Accessed on 20 June 2020) pipeline leaks in 2016, and its impact on the communities' environmental heritage. Following the UN 2008 declaration, in this paper, we discussed how the Cree First Nation communities' traditional environmental culture and practices became threatened, marginalized, and undermined through pipeline management politics and practices, particularly in Saskatchewan (known as Treaty 6 territory). As a result of these colonial (in this paper, colonization and colonialism are understood as practices of domination, which involves the subjugation of one people by another. These terms draw attention to how the settler state exercises power over Indigenous nations, exerting control with, for example, pipeline projects, the effects of those pipelines, and the use of Indigenous land) politics and practices, the Cree First Nation communities' sustainable environmental heritage are in danger. In relation to SDGs and UNESCO "2030" agendas, in our paper, we highlighted our learning experiences on how Cree First Nation communities want to protect their environmental heritage in collaboration with their traditional knowledge, practices, treaty rights, and guidelines as a driver of the Sustainable Development Goals.

In explaining ongoing colonization on Cree First Nation communities' environmental heritage rights, in this paper, we explore the extent to which the community members are affected by pipeline projects promoted by government and industry. How can new policy assist in including Indigenous peoples in safeguarding and managing their environmental and cultural heritage? Through a community-based research process, we endeavor to explore the community's perceptions of the community's colonial (i.e., government and industry) pipeline projects. Besides sharing circles and individual story sharing, data was also drawn from collective stories shared by Cree First Nation Elders, Knowledge Keepers, and leaders. In this paper, we tried to center on the community's perceptions of colonial environmental management projects (i.e., current management projects), and why Indigenous people see the current management practices as colonial. We tried to also explore the community's perspectives on protecting their environmental heritage by taking responsibility. We conclude by discussing UN declarations and Canadian policy and practices on protecting Indigenous environmental heritage.

\section{Methodology}

For this research, we used relational ontology and accountability as a theoretical framework, which benefits both researcher and participants in their efforts to decolonize by unpacking issues of power, voice, and possibility when hierarchical ways of being and knowing create and exploit constructed divisions among humans and with the morethan-human (Datta, 2015, and Wilson, 2008). We chose the relational approach because it consists of: (1) relational ways of thinking that prioritize collaboration between researcher and community and (2) community knowledge, community ways of knowing, community 
ways of constructing knowledge, and community ways of disseminating knowledge that is highly valued by all parties (Datta, 2018; Simpson, 2011; and Smith, 2012). We focused on transformative learning through the researchers' relational accountability and obligation to study participants and the site for several significant reasons. First, in relational ontologies, a researcher's relational accountability is fundamental to the research. Indigenous scholar Shawn Wilson (2008) suggests that a researcher's relational accountability involves fulfilling his or her relationship with the surrounding world. It requires researchers to be accountable to "all my relations." (p. 177) [10] Using relational accountabilities in our research framework, our goal was to foster respect for difference, build relational accountabilities into all stages of the research, and allow an ethical space of mutual engagement to take shape. Another critical characteristic of relational ontologies is the building of collaborative partnerships. Indigenous scholar Kovach (2005) researched collective responsibility [11]. According to Bastien (2004) "Knowledge is relational and dependent upon the relationships that are learned in childhood." [12] (p. 77) Our relationship with Saskatchewan Indigenous communities is well situated about these research goals. Through my (first author who is from a settler scholar of color community in Indigenous land known as Canada) graduate studies as well as leadership and professional activities over the last ten years, I have developed a strong relationship with Saskatchewan's FN, Métis, and non-Indigenous communities. In addition to institutions (Mount Royal University and the University of Regina in Canada) ethical approval, we followed Cree First Nation cultural protocols. The first author learned 25 traditional stories from the Cree First Nation Elders and Knowledge Keepers with the guidance of one of the Cree First Nation Knowledge Keepers, who has kindly agreed to be the second author of this paper. We followed institutional and Knowledge Keeper guidelines to protect research data, analyze stories, and write reports for the communities. We followed continuous forms of consent for this research, including for using their direct quotes for publication. We know that Indigenous knowledge varies according to community to community, land to land, and generation to generation. In this paper, our intention is not to generalize, predict, or compare. We shared our learning as a part of relational responsibilities with honour and respect to the community's knowledge and needs. We consider our learning to be a lifelong process of learning, unlearning, and relearning.

It is important to note that initially our study neither focused on SDGs nor on UNESCO "2030" agendas. [5] During our learning from various Elders' and Knowledge Keepers' stories, we can see that Cree First Nation perspectives on environmental rights are deeply interconnected with both SDGs and UNESCO “2030" agendas. Therefore, in this paper, our learning reflects on how Indigenous perspectives on environmental heritage can enrich both SDGs and UNESCO “2030" agendas. [5]

\section{Ongoing Colonial Politics and Practices on Indigenous Environmental Heritage Rights}

In this section, we share our learning experiences on the community's perceptions of colonial environmental management projects. Colonial environmental management projects are those projects developed by the Canadian government and non-governmental agencies. Here we discuss the Cree First Nation community's perceptions on the pipeline projects within their community. Participants (in this paper, we have not disclosed participants' information according to their requests) found that colonial management practices engendered feelings of broken trust, frustration, greediness, uncertainty, and danger for the community.

\subsection{Broken Trust from Researchers}

The Elders and Knowledge Keepers claimed that many researchers broke trust with communities, including university researchers as well as those from government and non-governmental industries. One of the Knowledge Keepers asked me as an academic researcher, "is not your [indicating first author Ranjan Datta] science objective? Should you [indicating first author] and other [academic researchers] research findings provide a 
similar answer if you both study with the same place and condition?" Another Knowledge Keeper further claimed that she has seen different academic researchers give different answers regarding pipeline leaks and their impacts on the community. She says that many academic researchers (i.e., scientists) from industry and government say that pipeline leaks were good for the environment, that "oil is good for your soil. Lets oil stay in your soil." However, when communities bring in independent researchers, they suggested that "oil is not good for our soil at all".

Independent researchers who were hired by the Cree First Nation community also suggested in their research (explained by a Knowledge Keeper) that "pipeline leaks killed many Microorganism from the soil and destroyed the soil fertility. Now, we learned that many governments and industry researchers did not give the right information. They hide much information and provide us with wrong information. We do not trust them anymore." Another Elder argued that many governments and industry scientists also manipulated their research processes.

I have seen many researchers collect very few water samples for their testing. From my education and 15 years of work experience, I know their [scientists] research samples are scientifically invalid. Industry researchers often collected their samples from low oil flow areas, and their samples showed no oil found. I know that their collected sample areas were not valid. How can we trust them?

Another Knowledge Keeper gave an example of why communities do not trust academic researchers by saying that

We have some tools to prove that the oil was coming down for years. They (industries and government) had those dogs that sniff hydrocarbons. They were detecting hydrocarbons on the river still as of last year. So it is still showing the effects. They said that pipeline leaks were good for the environment. They did not speak the truth to us. That was Huskies, researcher. But we don't think they are right. It was a false claim from their paid researcher.

Many community Elders and Knowledge Keepers expressed their frustration that, in most cases, "many researchers from government and industries did not include the community perspectives in their research. Communities knew nothing about how the research was done and what they found." One Knowledge Keeper further explained his frustration,

I have seen how Huskies [Saskatchewan Oil industry] came to our river and affected our water, fish, animals, and soil, but no one talks to me. Either they think we know nothing about this, or they want to hide something from us. That's why they did not include us, inform us of anything from their research. This is very frustrating.

All These Statements Showcase Why the Community Lost Their Trust in the Academic Researchers and How the Meanings of Research Became Colonial Tools in Western Research.

\subsection{Broken Trust from Industries and Government Officials}

Industries and government officials also did not provide the right information at the right time, and communities feel that the industries and government officials mislead them. For instance, one leader says, "Our governments and industries. So right from day one, we've been neglected to a dark corner, not even allowed to have a voice. So it's very frustrating for me to talk about this." Another leader says that "governmental officials did not tell the truth about pipeline leaks. I don't have any high expectations for anybody to change now. The problem is with the liars, once that lie has been exposed, keep on building other lies to cover the original lie." Leaders' statements exemplify how trust among Cree First Nation communities and governments was broken, as governments did not follow their responsibilities towards Indigenous rights. 


\subsection{Broken Treaty Responsibilities}

Communities explained that both provincial and federal government officials and industries had broken the Indigenous treaty (treaty rights in Canada referred to as Aboriginal rights (commonly referred to as Indigenous rights). The treaty rights are recognized and affirmed in Section 35 of the Constitution Act, 1982. They are also a vital part of the United Nations Declaration on the Rights of Indigenous Peoples, which the Government of Canada has committed to adopting). In regards to the responsibilities broken, one of the Knowledge Keepers said, "The spirit and intent of the treaty have been broken. All for capitalistic intent, a self-serving interpretation of a treaty. It's just a continuation of everything we face from day one." Another Elder explicitly explained how the governments had broken the treaty responsibilities.

The government of Canada took the share that we offered them, and then they took our stock and mismanaged it. Where is the accountability about taking our share? And how come we have to beg for our share? We are politically out to make meanness in such a fashion and lie to us when I trust money sits in Ottawa, earning one percent, and this is the government of Canada.

Another Elder describes the government's activities as lacking respect and sincerity for Indigenous people, "I think one of the gaps is a lack of respect and honesty from the government and the industries. There's a lack of commitment that respect. There's a lack of sincerity".

Many Knowledge Keepers also claimed that governmental officials did not explain how they have been violating their fiduciary duty to Indigenous communities in order to destroy Indigenous heritage rights. For instance, a Knowledge Keeper said that

The government of Canada does not see that they have a fiduciary obligation to First Nations. They won't define fiduciary. For me, a fiduciary means that our rights and interests come first. We should have our rights and interests come first.

Similarly, many Elders claimed that the government of Canada and industries were shameless and had the power to mismanage their land, water, and forest. One Elder said

The government of Canada, whoever is holding on to the treaty relation, has acted in a shameful, cheating, dishonourable, dishonest fashion. That's the real issue. It's not how First Nations are. The real problem is how Canada and the leadership in the provinces and the industry are acting. The government of Canada took the share that we offered them, and then they took our stock and mismanaged it. Where is the accountability about taking our share?

\subsection{Frustration}

Many leaders and Knowledge Keepers also expressed their frustration with the current forms of research and the researchers working on environmental heritage protection. Communities claimed many researchers lied to the communities many times. For instance, like many leaders, one said, "We do not trust researchers [referring to western researchers who do not talk to community members] any more. They lied to us many times. They said, oil is good for our soil and water. This is lied to us, this is immense frustration from industries researchers." Similarly, another Elder explained why the community Elders, Knowledge Keepers, and leaders think the research has been challenging for the communities "all our governments, industries, and researchers kept us in dark historically, we do not know what is going on".

\subsection{Greed}

Many Indigenous Elders, Knowledge Keepers, and leaders suggested that Canadian governments and industries violated Indigenous environmental rights because of greediness. Indigenous Elders explained that the Canadian governments and industries see Indigenous land, water, and forest as a source of profit maximization. For instance, one of 
the leaders said that "they [the government and industries] know how to make profits from our land, in most cases they do not care if our water, land, and agriculture become polluted by them. They [the government and industries] see our environment only as profit. This is greediness".

Similarly, another Elder explained how the Canadian government's and industries' greediness has been destroying Indigenous land and water, "The petroleum and hydrocarbons have been introduced in the water. It affected the vegetation with the ground of the earth. But I know it will not be over the next 50 years".

\subsection{Destruction of Environmental Rights}

Community Elders, Knowledge Keepers, and leaders frequently expressed that the pipeline leaks on their water destroy many Indigenous environmental rights, including Indigenous hunting rights, killing Indigenous medicine plants, and destroys sacred land, soil quality, and food sources. Thus, the communities do not hope that the government and industries will incorporate the knowledge of Indigenous community Elders, Knowledge Keepers, and leaders. For instance, one of the Elders said "both the government of Canada and industries are not including us in their decision-making process. We do not have hope with the government of Canada and industries." Another Elder explained his fear of uncertainty, "I'm thinking of my grandchildren and their grandchildren. What's going to be left for them by the time they are living here".

\subsection{No Support}

Communities noted many times that there was no support before, during, and after the pipeline leaks. Many Elders said that no government or industry officials contacted the communities. Communities did not get any form of support, including legal or financial support. Elders and leaders argued that it would be a challenge to protect many environmental rights without legal or financial support from the government. A Knowledge Keeper also express that there is no certainty,

So when you [showing first author as a researcher] talk about free prior and informed consent, corporate social responsibility. No consent and corporate social responsibility exist for the First Nations people. There is no legal and political support available to Indigenous communities to ensure that public participation processes are practical and durable. No such thing exists, nothing.

According to participants' perspectives, the government's and industries' conceptions of environmental management diverge from the community's understanding and practices. Taken together, the detrimental effects of current management projects (exploitation, frustration, fear, and danger) challenge the legitimacy of the projects and the organizations administering them. Using examples from participant conversations, we, as an academic researcher and Knowledge Keeper, learned that the current land, water, and forest management projects (both governmental and non-governmental agencies) were far different from the community's traditional management practices. Most of the Elders, Knowledge Keepers, and leaders claim that the current colonial environmental management practices have created the visible negative impacts discussed above as well as invisible impacts on the community's everyday life.

\section{Indigenous Perspectives on How to Protect Environmental Heritage}

The research also explores why and how the community wishes to protect environmental heritage, such as traditional land and water culture and practices. Indigenous people of the community invite all of us to understand the root causes of colonial problems and take an active role in the healing process. They also explain environmental rights from the traditional ways of life, practices, and culture. Indigenous ways of life are their environmental heritage, as their traditional ways of life respect and honor both human and non-human. Traditional life considers the environment as a part of their family, body, and practice. Therefore, the environment and humans are in a relationship, and they take care 
of each other. Many Elders and Knowledge Keepers suggested that it is difficult to understand Indigenous environmental heritage without understanding Indigenous traditional knowledge and practices. Indigenous people are individually and collectively responsible for the well-being of all members of society, of future generations, and the maintenance of all parts of creation.

Indigenous relationships make Indigenous people responsible; it is their responsibility to be the caretaker of all that is on Earth; therefore, they are responsible for building new forms of environmental heritage rights for all. The responsibilities of the community's youth are the driving forces behind the development of Indigenous culture being reflected in the institutions and systems of Indigenous people: follow treaty responsibilities; respect Elders' and Knowledge Keepers' knowledge of Indigenous land-water rights; own and lead research; develop a research lab; build community capacity; create a communityled impact assessment; follow collaborative decision-making; center community needs; acknowledge Elders and Knowledge Keepers as scientists; and find the balance between development and protection.

Members of the Cree First Nation community were aware of their responsibility and knew they needed to maintain this balance for their environment. Their responsibilities for protecting their environmental heritage suggest not simply "adding on" western forms of management but rather centering Indigenous ways of knowing within the new forms of environmental heritage to learn, act, and belong. Through these responsibilities, youth believe they can overcome the severity of the state's environmental management crisis and lead a radical departure from current development-dominated knowledge and education models.

With a situational and holistic view on sustainability, this study reveals the community's relational responsibilities. The community's Elders and Knowledge Keepers see their relational responsibilities as protecting the community's traditional environmental management practices and building a sustainable livelihood. According to the United Nations (2018), youth is a significant stakeholder for community development and sustainability. Similarly, Collins (2004) found that today young people possess more substantial power and potential to create change on a global and local level than any previous generation. Likewise, others $[4,12]$ have stressed that the youth's collective responsibility as environmental leaders is vital to the sustainability of Indigenous communities. In reflecting on their lives, the Cree First Nation's sense of collective responsibility as leaders and role models is essential to achieving sustainability. As understood and practiced by the Cree First Nation communities, environmental heritage is built around complexity, relationships, and responsibility. These relational knowledge traits are an integral part of the physical, spiritual, and mental dimensions of the community's systems of values and norms.

We learned that the Cree First Nation communities have observed that their land, water, and animals have been destroyed by pipeline leaks and other developmental projects that have been profitable for the Canadian government and private industries. However, community members were not hopeless; they trust that their youth can offer new possibilities and fight for their environmental heritage rights and protect nature. The dreams, hopes, and hard work of the Cree First Nation and their youth offer new possibilities for western environmental science and can help rebuild environmental heritage rights for the community, nationally and beyond.

We also learned that Cree First Nation's understanding of environmental heritage could help them build a self-sufficient economy and protect their ecosystem and contribute to the state's management policies and create new forms of sustainability education practices. The work done within Indigenous communities has the potential to inform western environmental educators, researchers, policy-makers, and activists, and give them a more in-depth understanding. Bringing Indigenous sustainability and the non-Indigenous knowledge system about environmental sustainability together will allow for the emergence of a healthy new relationship between Indigenous and non-Indigenous peoples.

The Cree First Nation's responsibilities for their environmental heritage emerge from the family, the community, and the clan structure, and are actualized through a division 
of labor that benefits the whole group. Individual actions may help the individual, but they must also benefit the whole group. They believe the environment has its own agency and the power to manage itself. Indigenous people believe in relationships, and their relationships make them responsible to both humans and non-humans. In this relationship, there was not only equality with the other spirits of sustainability, but there was equality with all beings (both human and non-human) (Latour, 2004). No being (human and nonhuman) was any less than the other; each had a role to perform in creating sustainability. Each animal and plant is simply one piece of the overall scheme of things, and each has something to contribute that is valued equally with all others. Indigenous Elders and Knowledge Keepers explained the Indigenous youth's responsibilities for their environmental sustainability as a "movement" that can provide opportunities for the youth and their communities to explore the meaning of land-water management and its facultiessources of wisdom, values bestowed, and voices harnessed in the process of place-making. The responsibilities of Indigenous youth have a profound impact on the inclusion and recognition of Indigenous ways of protecting sustainability and its global implications.

This research has found that Cree First Nation's responsibilities for environmental heritage can have extensive positive impacts on protecting the land-water, on traditional management, and on building healthy, sustainable local economies with the wisdom and tools to strengthen their relationships to the land, and to continue to decolonize their communities and environment.

\section{Discussion and Conclusions}

Through this research, we (Cree First Nation Knowledge Keeper and settler of colour scholar) learned that the current Canadian governmental and non-governmental management practices (i.e., colonial) violated UN Indigenous declarations (2008) [13,14]. As the community suggested, academics, government and non-governmental policy-makers, and activists must begin by acknowledging and grappling with their colonial as well as historical roots. Unveiling government and non-governmental agencies' complicity in colonial dominion over space requires careful tracking of environmental policy-makers' historical role in colonialism's processes and rendering those processes visible to all of us. The Cree First Nation communities' traditional environmental practices and knowledge became marginalized economically, socially and politically. They are also often pushed to the margins of mainstream consciousness. Current Canadian governmental and nongovernmental management practices are explicitly environmentally racist and colonial because they misrepresent and ignore Indigenous traditional environmental methods. The long history of ongoing colonization denies the Cree First Nation community's sustainable environmental heritage, practices, and sustainability, as well as the means through which poverty, health problems, land appropriation, and environmental degradation have become endemic in the region.

Indigenous peoples' understanding and practicing of environmental heritage are interconnected with SDGs. As Cree First Nation Elders and Knowledge Keepers suggested, they have maintained sustainable practices with their environment for thousands of years. Cree cultural tradition, traditional knowledge systems, and languages contribute directly to biological and cultural diversity, spirituality, food security, and ecosystem health. Their environmental heritage knowledge and practices can help to promote diets that are diverse and sustainable. However, the current approach (they call it colonial) created many challenges, including pollution of water and land, destruction of traditional food sources, deforestation, and land degradation. Therefore, Indigenous peoples' critical role and traditional practices in protecting environmental heritage have been recognized in the 2007 UN Declaration on the Rights of Indigenous Peoples (UNDRIP) [14]. Our study shows how to achieve SDGs in environmental heritage through Indigenous communities' leaderships, guidelines, and recommendations. Cree First Nation Elders and Knowledge Keepers suggested how to create meaningful implementation of SDGs to protect their environmental heritage. For instance, in this study they suggested to us (as a researcher 
and community member) how to take responsibilities to promote the treaty rights in energy management and efficiency improvement. As Elders and Knowledge Keepers explained, to investigate and take advantage of Indigenous and traditional designs and techniques, where proven to be better adapted to local climates and environmentally sound. They also recommended how to utilize Indigenous and/or traditional energy resilience methods, where proven to be better adapted to local climates and environmentally sound, to provide localized models for sustainable energy management. Last but not least, it is important to respect, encourage, and support cultural norms that promote the sustainable use of resources, energy practices, and economic activities. All of the Indigenous perspectives are interconnected with SDGs to protect Indigenous environmental heritage. We have learned that Indigenous perspectives on their environmental heritage connected with four SGDs, including: Goal 3, Good Health and Wellbeing, Goal 10, Reduced Inequalities, Goal 13 Climate Action, Goal 15, Life on Land, and Goal 16, Peace, Justice, and Strong Institutions. Indigenous environmental heritage rights-both tangible and intangible - and creativity are resources that need to be protected and carefully managed by Indigenous community leadership and guidelines. They can serve both as drivers for achieving the SDGs as well as enablers, when environment-forward solutions can ensure the success of interventions to achieve the SDGs. We have learned from the community that the SDGs need to be reshaped from the community perspectives so that they help to build community capacity, speck community needs from the economic, cultural, social, and environmental.

Outsider, for-profit management projects are highlighted in the data as a form of colonial oppression imposed upon the Cree First Nation communities. Participants emphasized the role of for-profit companies in contributing to exploitation, displacement, deforestation, species extinction, and poverty, which has devastated the community. The term outsider is used to depict invasive for-profit companies, which may be understood through drawing on Edward Said's (1993) seminal work Orientalism. Said claimed that the imposition of the colonial outsider over local populations requires an unequal system of force, leading to processes of othering. According to Said, the outsider creates forms of oppression and power inequality and imposes them upon local people, much like the relationship between the occident and the orient and the hegemonic nature of colonial power. Escobar (2008) gave an in-depth explanation of how capital accumulation in globalized monoculture environmental resource management creates profit for owners and removes local people, their traditional practices, and their identity. Elders and Knowledge Keepers emphasized that the various entities imposing monoculture and for-profit management projects and policies onto the Cree First Nation communities have marginalized, or "othered", them on their ancestors' land.

One of the main issues revealed by this study of a Cree First Nation community's diverse and relational understandings and practices of land and water management involves the impacts of the colonial nature of contemporary agencies' (both governmental and non-governmental) resource management policies. The study's findings revealed three major impacts that can be attributed to the effects of colonialism: the privileging of non-Indigenous natural resource management knowledge over Indigenous knowledge, the dominance of the state administrative structure over the Indigenous structure, and the power of outsider profit-oriented development projects over Indigenous land and forests.

The consequence of valuing non-Indigenous knowledge over Indigenous knowledge has a significant colonial impact on the Cree First Nation community's traditional natural management practices. Participants argued that Indigenous understandings and practices were significantly undermined by outsiders' (governmental and non-governmental) land policies and projects. Indigenous scholars Tuck and Yang (2012) showed how a settlercolonial framework privileges settler knowledge over Indigenous knowledge. [15] Other researchers have argued $[7,8,15,16]$ that outsider management practices on Indigenous lands can be a significant barrier to Indigenous sustainable practices due to both the consideration of land as profitable, static, and exploitable, and processes that disembody social life from local connections. 
Indigenous treaty rights, as stated by both the United Nations Declaration on the Rights of Indigenous Peoples and the Truth and Reconciliation Commission's Calls to Action, gave specific guidelines and measures for protecting Indigenous environmental heritage rights, meaningful consultations, culturally relevant supports, and an increase in the use of restorative justice practices for Indigenous peoples. Non-Indigenous environmental management knowledge can have dangerous consequences for the local environment. Theorists have argued $[7,8,15,16]$ that outsiders' management practices undermine traditional communal practices through different development projects. Participant Elders, Knowledge Holders, and leaders expressed that current management policies have eroded Indigenous traditional environmental management knowledge and led to species extinction, illegal logging, deforestation, soil degradation, illegal migration, land appropriation, and poverty in the community.

Author Contributions: The study was conceptualized by R.D. and W.P.M., and participating Elders and Knowledge Keepers, Leaders and Indigenous organization. The methodological approach and data analysis involved R.D. guided by W.P.M. and using traditional protocols and consent from representatives of participating communities. Data collection and verification of data with participating individuals and partners was led by R.D. Data analysis was led by R.D. The manuscript was prepared by R.D. with input from all authors. All authors have read and agreed to the published version of the manuscript.

Funding: SSHRC Banting Postdoctoral Fellowship 2018 and the Canada Research Chair Funding 2020 for this research.

Institutional Review Board Statement: University of Regina (ethical approval \# 2018-237) and the Mount Royal University (ethical approval \# 7102351).

Acknowledgments: We are sincerely grateful to the Cree First Nation communities' Elders and Knowledge Keepers in Saskatchewan, Canada, who supported our research, taught us, guided us, and shared their stories about their needs and expectations. Cree First Nation Elders and Knowledge Keepers are scientists for their community, and their knowledge has been scientifically proven for thousands of years. This paper is one of the outcomes of our responsibilities. I (first author) am deeply grateful to them for considering me as a relative, and I will be accountable for our relationship. We know learning is a lifelong process. We acknowledge the SSHRC Banting Postdoctoral Fellowship 2018 and the Canada Research Chair Funding 2020 for this research. We are also grateful to Margot Hurlburt at University of Regina, SK, Canada who is in our research supervisor.

Conflicts of Interest: There are no conflict of interest reported by any of the authors.

\section{References}

1. Wegener, C. The 1954 Hague Convention and Preserving Cultural Heritage; Archaeological Institute of America: Boston, MA, USA, 2010.

2. Prott, L.V. Strengths and Weaknesses of the 1970 Convention: An Evaluation 40 Years after Its Adoption. Background Paper. 2011. Available online: http://www.unesco.org/new/fileadmin/MULTIMEDIA/FIELD/Brussels/pdf/strengths\%20and\%20 weaknesses\%20of\%20the1970\%20convention.pdf (accessed on 20 June 2020).

3. Graber, C.B. The new UNESCO Convention on Cultural Diversity: A counterbalance to the WTO? J. Int. Econ. Law 2006, 9, 553-574. [CrossRef]

4. Whyatt, S. Thematic Report A/HRC/23/34. 2018. Available online: https://www.ohchr.org/Documents/Issues/CulturalRights/ 10thAnniversary/Sarah_Wyatt.pdf (accessed on 15 June 2020).

5. United Nations Educational Scientific and Cultural Organization (UNESCO). UNESCO's Engagement with Indigenous Peoples. 2018. Available online: https:/ / unesdoc.unesco.org/ark:/48223/pf0000261839.page $=4$ (accessed on 15 May 2020).

6. Agrawal, A. Indigenous knowledge and the politics of classification. Int. Soc. Sci. J. 2002, 173, 287-297. [CrossRef]

7. Berkes, F. Evolution of co-management: Role of knowledge generation, bridging organizations and social learning. J. Environ. Manag. 2009, 90, 1692-1702. [CrossRef] [PubMed]

8. Berkes, F. Sacred Ecology: Traditional Ecological Knowledge and Resource Management; Taylor \& Francis: Philadelphia, PA, USA, 1999.

9. Briggs, J. The use of indigenous knowledge in development: Problems and challenges. Prog. Dev. Stud. 2005, 5, 99-114. [CrossRef]

10. Wilson, S. Research Is Ceremony: Indigenous Research Methods; Fernwood Publishing: Winnipeg, MB, Canada, 2008.

11. Kovach, M. Emerging from the margins: Indigenous methodologies. In Research as Resistance: Critical, Indigenous, \& Anti-Oppressive Approaches; Brown, L., Strega, S., Eds.; Canadian Scholars' Press: Toronto, ON, Canada, 2005; pp. 19-36. 
12. Bastien, B.; Kremer, J.W. Blackfoot Ways of Knowing: The Worldview of the Siksikaitsitapi; University of Calgary Press: Calgary, MA, Canada, 2004.

13. Coulter, R.T. UN Declaration on the rights of indigenous peoples: A historic change in international law. Idaho L. Rev. 2008, 45, 539 .

14. UN General Assembly, United Nations Declaration on the Rights of Indigenous Peoples: Resolution/Adopted by the General Assembly, 2 October 2007, A/RES/61/295. Available online: https://www.refworld.org/docid/471355a82.html (accessed on 16 July 2021).

15. Tuck, E.; Yang, K.W. Decolonization is not a metaphor. Decolonization Indig. Educ. Soc. 2012, 1, 1-40.

16. Escobar, A. Latin America at a crossroads. Cult. Stud. 2010, 24, 1-65. [CrossRef] 